\title{
Research and Practice on the Teaching of Analog Electronic Technology under the Innovative Talents Training Mode
}

\author{
Ting Zhang and Yun Shi \\ Information Engineering College, Xijing University, Shanxi Xian 710123
}

Keywords: Application type; Analog electronic technology; Teaching research

\begin{abstract}
In order to improve college students' practical ability and adapt to the demand pattern of training applied and innovative talents, it is of great practical significance to study and explore the teaching of analog electronic technology that is an applied basic course. This paper studies the nature, research content, research methods and expected goals of the course of analog electronic technology to improve the level of college students.
\end{abstract}

\section{Introduction}

The analog electronic technology is an important branch of applied electronic technology. It is a professional basic course offered by several majors in colleges and universities, and also it is a applied and practical discipline, which plays a significant role in cultivating students' creative ability in power. With the application of innovative talents training objectives and the implementation of "one wing and one wing" talent training mode, more and more attention has been paid to the discipline competition, and contests related to analog electronic technology courses includes: Electronic design competition, electronic product design and manufacturing and the Internet of things and other related professional competition. The aim is to examine the students' hardware design and practical ability, which reflects the spirit of the Shaanxi Province ordinary undergraduate colleges and universities to the application technology type colleges and universities transformation development pilot work plan.

At present, most of analog electronic technology teaching courses in colleges and universities are aiming at the students' mastery of the semiconductor structure, the basic theoretical analysis and the calculation of the index parameters. There is no emphasis on the signal operation, signal processing and signal generation circuit, thus can enable students to master the basic knowledge of analog electronic technology and understand the scope of its application, but they are lack of circuit design and practical operation ability. Actual participation in the project, it is impossible to lay their hands on the application, learning cannot be well reflected, which is the performance of the theory and practice of teaching out of touch.

\section{Analog Electronic Technology Course of Our School}

The teaching environment of analog electronic technology course in our university is mostly in the classroom. There are some problems such as the lack of curriculum content and practical problems, the lack of curriculum content, and so on. The teaching mode has changed from the traditional teaching mode to the project teaching mode, from the introduction of the project, process analysis, hardware circuit design, etc., and through the Multisim simulation tools to simulate the working process of the circuit, the teaching effect has been improved, but there are still deficiencies. From the beginning to the end of the classroom is still only a teacher in practice, so students can not personally familiar with the operation of the software and hardware circuit production methods, it is difficult to train students to master the basic methods and basic procedures for the implementation of the project. The proportion of experimental class hours is small and experimental equipment is experiment box, so students just finished the circuit connection in the experimental box, and are unable to train hardware circuit design, welding and debugging ability, and it hard to master usage method of the oscilloscope, multimeter and voltage source experimental tools, which influences the quality of practice teaching and seriously affects the preparatory work of the relevant disciplines in 
our school competition. Students enter for the competition, followed by intensive training and a shorter training spent training the basic knowledge and basic operational. If we can strengthen the cultivation of practical ability focusing on training sessions with challenging topics in normal times, the preliminary work will be more prepared.

According to the analysis above, in the context of the transformation of applied technology type colleges, adhering to the principle of "cooperative education and practical education", under the promotion of "project" and "flipped classroom" teaching mode, the research and practice on the teaching of analog electronic technology is a urgently problem to be solved.

\section{Research Contents}

Based on the character and actual demand of analog electronic technology course, in the course of teaching, the content of project is closely integrated with practice, and the teaching mode of the combination of project teaching and flipped classroom teaching mode is implemented. The teaching process is the combination of theory, simulation and hardware, that is, on the basis of explaining the theoretical knowledge, through the Multisim or EDA simulation software to simulate the circuit principle, then the students finish the debugging hardware circuit and analyzing the experimental waveform. To cultivate students' practical ability theory, and familiar with usage of common instruments, learn how to think by them in practice, so as to improve the circuit design and analysis ability, laying a good foundation for academic competitions, graduation design and innovation training project. The specific contents are as follows.

1) According to the characteristics of analog electronic technology courses and related disciplines, combined with the actual needs, summed up the common knowledge points, and integrated all of them into the project;

2) The design of the project. Join them into the course content, which has the project actual value, to stimulate students interest in learning;

3) Study the suitable teaching mode. Cultivating students' project analysis, design and execution ability, and then complete the construction of "a teacher a lesson " of analog electronic technology;

4) The implementation of the process. Establish the teaching methods "theory - Software hardware,", focusing on training students to design and practice the ability to prepare for the graduation design and discipline competition;

5) Study the examination method. Do not carry out teaching effect feedback regularly to improve teaching quality.

\section{Research Methods}

To stimulate students' interest in learning and improve the practical ability and achieve the application of technology talent type university, the reform is mainly from teaching methods and teaching modes, teaching and practice etc. to reform, the research carried out in accordance with the basic steps:

1) Research. Including literature research and theoretical research, in-depth understanding of the student bases, competition and actual needs and other aspects;

2) Adhere to the principle of combining theory with practice, planning the content of the project, highlighting the practical;

3 ) Pay attention to the effect of teaching, changing from the traditional teaching methods to the project, flip the classroom teaching mode to cultivate students' ability to analyze problems, solve problems and innovation training;

4) To train the students' ability of circuit design and analysis, through the software simulation circuit, then debugging the hardware circuit;

Select the project oriented course and adhere to the principle of combining theory with practice, pay attention to the practice of curriculum design, combined with the actual needs of the 
competition, and the project has the actual value of the project; Introduce software EDA or Multisim simulation demonstration into the theory of teaching. Improve the proportion of practice teaching. Take the project teaching and the combination of flipping the classroom teaching mode, adhere to the "teaching, learning and doing" principle, the students hands-on, cultivate students' innovative thinking ability; use the curriculum design and the pre race training time to learn the contents of depth training, challenging topics to prepare for contest.

\section{Expected Goal}

1) The teaching mode of combining the project and the flipped classroom are carried out;

2) To improve the students' learning enthusiasm, initiative and practical ability, to cultivate students' ability of circuit design and analysis, also various competitions will be the basic training stage ahead of time, provides to the subsequent development for students, improve students' competitive power competition;

3 ) Complete the construction of the course of analog electronic technology " a teacher a lesson".

\section{References}

[1] Zheng-Mei L I, Cui D, Fang Y, et al. Research on the experimental teaching reform of analog electronic technology based on excellent engineer[J]. China Medical Equipment, 2016.

[2] Liu X, Li C, Tang L. Exploration of Analog Electronic Technique Reform in Practical Teaching[J]. China Modern Educational Equipment, 2016.

[3] Li-Li W U, Cao Q, Bin-Qiang M A, et al. Study on Teaching Reform of the Electronic Information Major based on the "Plan for Cultivating Excellent Engineers"[J]. Jiangxi Science, 2013.

[4] Zhou H, Huang C, Qian Y U, et al. Study on Teaching Reform of Mechanical Design Based on the Excellent Engineer Education Training Program and CDIO $[\mathrm{J}]$. Modern Manufacturing Technology \& Equipment, 2014.

[5] Wang X X, Xiao-Hai L I, Ding H J, et al. Research and practice on teaching reform of mechanical engineering curriculum based on EIP-CDIO1[J]. Heilongjiang Science, 2016.

[6] Shao J, Sui X, Chen S. Academic Management of Excellent Engineer Training Program for Specialty of Mechanical Design \& Manufacture Based on CDIO Model[M]. 2013.

[7] Liu R, Feng C, Zhang Y, et al. Innovative Training Model of Talents for Pharmaceutical Engineering Specialty Based on CDIO Concept[J]. Pharmaceutical Education, 2016.

[8] Sun S, Wu Y, Lu Q, et al. Conceive and Construction of Engineering Training Model Based on the Concept of International CDIO Engineering Education[M]// Engineering Education and Management. Springer Berlin Heidelberg, 2012:437-444.

[9] Lu Q Q, Wu Y F, Sun S L. The Construction and Practice of Teaching Method for Mechanical Principles Integration Course Based on $\mathrm{CDIO}[\mathrm{J}]$. Advanced Materials Research, 2012, 591-593(591-593):2171-2174.

[10]Liu X. On the Teaching Reform of Outstanding Applied Financial Management Personnel Training Mode Based on the Concept of CDIO_-Taking Changzhou Institute of Technology for example[J]. Guide of Science \& Education, 2016.

[11]Ding H Z. The Reform Based on CDIO Concept of Training Mode of Professionals in Electrical Automation Technology[J]. Journal of Shazhou Professional Institute of Technology, 2013.

[12] Han N. A discussion of cultivating undergraduate talents of tourism management based on the CDIO mode.[J]. Journal of Chemical \& Pharmaceutical Research, 2014.

[13]Aiping X U. The Research on the Talent Training Mode of the Undergraduate Students in Hospitality Management Based on the CDIO Theory_-Take Shanghai Polytechnic University as an Example[J]. Journal of Shanghai Second Polytechnic University, 2016.

[14]Bai J, Song Y. Research and practice on the training mode of the core competence about the 
application-oriented electrical information engineering undergraduate[J]. 2016, 24:02016. 